\title{
Pregnancy Induced Hypertension in Kabo Local Government Area of Kano State, Nigeria
}

\author{
Aruaye Afeye Obada ${ }^{1}$, Abubakar Aliyu Abba $^{2}$ and Aondover Eric Msughter ${ }^{3 *}$ \\ ${ }^{1}$ Department of Microbiology, University of Calabar, Nigeria \\ ${ }^{2}$ Lecturer at Federal Polytechnic Mubi, Adamawa State, Nigeria \\ ${ }^{3}$ Lecturer in the Department of Mass Communication, Skyline University Nigeria
}

*Corresponding author: Aondover Eric Msughter, Lecturer in the Department of Mass Communication, Skyline University Nigeria

\section{ARTICLE INFO}

Received: 蔧 October 08, 2021

Published: 蔧 October 22, 2021

Citation: Aruaye Afeye Obada, Abubakar Aliyu Abba, Aondover Eric Msughter. Pregnancy Induced Hypertension in Kabo Local Government Area of Kano State, Nigeria. Biomed J Sci \& Tech Res 39(4)2021. BJSTR. MS.ID.006321.

Keywords: Pregnancy Hypertension; Gestational Hypertension; Hypertension; Kabo

\begin{abstract}
Pregnancy Induced Hypertensions (PIHs) are responsible for 70,000 maternal deaths universally, killing one woman every 11 minutes. Nigeria, in 2014, recorded the prevalence of pregnancy induced hypertension and was estimated to be about 20.8\% among pregnant women attending antenatal clinics in Teaching Hospitals in South-South. Among the causes of maternal mortality, it ranks second only after hemorrhage. Thus, this study interrogates pregnancy induced hypertension in Kabo Local Government Area of Kano State. The study used Interpretative Phenomenological Analysis (IPA). Purposive sampling method was used in selecting the 22 respondents for in-depth interview. The study found that the signs of pregnancy induced hypertension in Kabo Local Government include chest pain, headache, blurred vision, dizziness, pedal oedema and epitaxies. The study further discovered that most of the risk factors are multiple gestations, elderly prim gravida, high parity, polyhydramnios, essential hypertension, kidney disease, high salt intake, obesity and stress. The study concludes that global pregnancy induced hypertension caused high maternal death in pregnant women in Kabo. The study recommends that pregnant women should visit the hospital regularly, especially to check their blood pressure and should be educated about the signs of pregnancy induced hypertension.
\end{abstract}

Abbreviations: PIHs: Pregnancy Induced Hypertensions; IPA: Interpretative Phenomenological Analysis; ANC: Antenatal Care; SDG: Sustainable Development Goal; MDGs: Millennium Development Goals; IUGR: Intrauterine Growth Restriction; NIS: Nationwide Inpatient Sample; OR: Odds Ratio; ISSHP: International Society of the Study of Hypertension in Pregnancy; HDP: Hypertensive Disorder of Pregnancy; IPA: Interpretative Phenomenological Analysis; TRA: Theory of Reasoned Action; TBP: Theory of Planned Behavior; HELLP: Hemolysis, Elevated Liver Enzymes, Low Platelet; ACE: Angiotensin Converting Enzyme; RASS: Renin Aangiotensin Aaldosterone System; ARBs: Angiotensin Receptor Blockers

\section{Introduction}

Despite the high technological inclination in the 21st century, especially in the area of health, the rates of maternal mortalities and morbidities are still very high in women worldwide. The occurrence of maternal hypertensive disorders is found to have about 20.7 million women in 2013 and about $10 \%$ of pregnancies globally are complicated resulting from pregnancy induced hypertension
Sharma, et al. [1]. In the United States, hypertensive disease of pregnancy affects about $8 \%$ to $13 \%$ of pregnancies Mohan, et al. [2]. Annually, an estimated 2.9 million babies die during the neonatal period and 2.6 million babies are stillborn around the world due to PIH. According to WHO (2018), the rate of stillbirth is 21.9 per 1000 births in women with a pregnancy induced hypertension (PIH) and 
normotensive women 8.4 per 1000 live births in china Xiong T, et al. [3]. Pregnancy Induced Hypertensions (PIHs) are responsible for 70,000 maternal deaths universally, killing one woman every 11 minutes Magee, et al. [4]. It is the second leading cause of maternal mortality in Bangladesh, according to the Bangladesh Maternal Mortality Survey (2017), about 24 percent of the country's maternal deaths are caused by pre-eclampsia/eclampsia (PE/E) NIPORT, et al. [5], which affects women during pregnancy, childbirth, as well as postpartum. Factors, such as lack of health care provider capacities to detect, prevent, and manage PE/E, late referrals of HIP clients, late attendance and lack of antenatal care (ANC) and awareness about PE/E among communities have been associated as reasons for most of these preventable deaths Warren, et al. [6].

Deruelle, et al. [7] reported that about 25 percent of women with PIH, especially those with a dangerous condition, experience a decline of end-organ functions during puerperium (the 6 to 8 weeks after delivery, during which pregnancy changes return to baseline). PE early in pregnancy (less 34 weeks of gestation), presenting in a severe form, or persistence of proteinuria more than three to six months after delivery suggests possible chronic hypertension or renal disease. Women with pre-eclampsia are also at increased risk for venous thromboembolism in the postnatal period (after delivery), and those women should receive thromboembolic prophylaxis after delivery until they are fully recovered, usually within four to six weeks RCOG [8]. Similarly, women with preterm pre-eclampsia and gestational hypertension have been found to develop persistent cardiovascular impairment one year after delivery Melchiorre, et al. [9], including other chronic diseases such as chronic hypertension, stroke, renal disease, diabetes mellitus, and ischemic heart disease. Infants born to women with PIH also require special attention in the immediate postnatal period due to a combination of short and long term risks. Standard international guidelines recommend lifelong care and monitoring, or a minimum of care and monitoring for six months to one year after delivery. Studies propose that complications associated with PIH continue in the immediate postnatal period and longer NICE [10].

One of the goals of the United Nations Sustainable Development Goal (SDG) is to reduce the global maternal mortality ratio to less than 70 per 100,000 live births by 2030 United Nations [11]. The SDGs aim to uphold the momentum of the Millennium Development Goals (MDGs), which in its relentless effort catalyzed a global reduction in maternal deaths from approximately 390,000 in 1990 to 275,000 in 2015 Graham, et al. [12] United Nations, 2018). The strains of maternal mortality remain unduly borne by women in less-developed countries, particularly in sub-Saharan Africa (66\%, 201,000 deaths) and southern Asia (22\%, 66,000 deaths). One of the leading causes of maternal death (and disability) worldwide is pregnancy induced hypertension Payne, et al. [13]. The statistical figures of this problem in less developed countries have varied from $4.0 \%$ to $12.3 \%$ (Sebastia et al., 2015; Berhe et al., 2018). Pregnancy induced hypertension is also one of the major leading causes of pregnancy associated with morbidity and it is the most recurrent cited cause of maternal death Ethiopian Journal of Health Science [14]. Despite the fact that hypertensive conditions in pregnancy is leading causes of maternal morbidity and mortality during pregnancy, little is known about its magnitude among pregnant women in Kano and, specifically in Kabo Local Government Area. This study therefore aims to fill this gap by considering pregnancyinduced hypertension, the signs, associated risk factors and prevention and management among pregnant woman attending antenatal service in Kabo.

\section{Basic Tools of Scientific Inquiry}

The study was guided by the following research questions:

1. What are the signs of pregnancy induced hypertension among women in Kabo Local Government Area of Kano State?

2. What are the risk factors associated with pregnancy induced hypertension among women in Kabo Local Government Area of Kano State?

3. What are the preventions measures of pregnancy induced hypertension in Kabo Local Government Area of Kano State?

\section{Literature Review}

Pregnancy Induced Hypertension (PIH) known as toxemia or preeclampsia is a form of high Blood Pressure (BP) in pregnancy. $\mathrm{PIH}$ is one developing after 20 weeks of gestation without other signs of preeclampsia. It is a known cause of premature delivery, intrauterine growth restriction (IUGR), placental abruption and fetal death, as well as maternal mortality and morbidity (Gombe et al., 2011). It is characterized by either blood pressure levels of $140 / 90 \mathrm{~mm} \mathrm{Hg}$ or higher after 20 weeks of gestation, or a blood pressure rise greater than $30 / 15 \mathrm{mmHg}$ from early or prepregnancy baseline or a rise of mean arterial pressure of more than $105 \mathrm{mmHg}$. This due to the development of arterial high pressure in a pregnant mother after 20 weeks of gestation, which may or may not have protein in urine and has a blood pressure of or more than $140 / 90 \mathrm{mmHg}$ (National Guidelines for Quality Obstetrics, 2004). Of all the pregnancy related complications in the world, pre-eclampsia and eclampsia present $10 \%$ major causes of maternal and prenatal morbidity and mortality, with pre-eclampsia affecting 5-7 \% of all pregnancies, Srinivas, et al. [15]. Hypertensive disorders during pregnancy is among the leading cause of maternal and fetal mortality in obstetric practice that can prevent the baby from getting enough blood and oxygen harming their liver, kidney, brain, and heart, causing end organ damage, Palacios, et al. [16]. 
Pregnancy induced hypertension is a major cause of maternal morbidity and mortality in the United States. There is an approximately one maternal death due to preeclampsia-eclampsia per 100,000 live births, with a case-fatality rate of 6.4 deaths per 10,000 cases Livington, et al. [17]. The outcome of hypertension in pregnancy is affected by multiple factors. These include gestational age at onset, severity of disease, and the presence of comorbidities like diabetes mellitus, renal disease, thrombophilia, or pre-existing hypertension Heard, et al. [18]. Similarly, a study conducted in Latin America and Caribbean, Pakistan, New York, and Sri Lanka identified null parity, multiple pregnancies, history of chronic hypertension, gestational diabetes, fetal malformation and obesity as the risk factors for developing pregnancy induced hypertension Dolea [19]. Furthermore, life-threatening maternal age (less than 20 or over 40 years), history of PIH in previous pregnancies, preexisting diseases like renal disease, diabetes mellitus, cardiac disease, unrecognized chronic hypertension, positive family history of PIH, which shows genetic susceptibility, psychological stress, alcohol use, rheumatic arthritis, very underweight and overweight, and low level of socioeconomic status are the risk factors for PIH Abeysena, et al. [20].

One important aspect of diagnosing and managing hypertension in pregnancy is presiding out secondary causes. These causes can add to both the maternal, fetal morbidity and mortality. Records from the Nationwide Inpatient Sample (NIS) of hospitalizations for delivery between 1995 and 2008 showed that out the patients with chronic hypertension (1.15\% of the sampled population), $11.2 \%$ had secondary causes. Secondary hypertension had higher odds of adverse maternal and fetal outcomes when compared to essential hypertension (odds ratio (OR), 11.92 vs 10.18 for preeclampsia, 51.07 vs 13.14 for acute renal failure, 4.36 vs 2.89 for spontaneous delivery < 37 weeks) Bateman, et al. [21]. Examples of secondary forms of hypertension are chronic kidney disease (most common cause), hyperaldosteronism, Reno vascular disease, obstructive sleep apnea, Cushing's syndrome, pheochromocytoma, thyroid disease, rheumatologic diseases (e.g. scleroderma or mixed connective tissue disease), and coarctation of the aorta; lack of understanding on how to diagnose and treat these conditions during pregnancy may lead to a higher morbidity and mortality Malha [22].

\section{Pregnancy Induced Hypertension in Nigeria}

In Nigeria, an incidence of $20.8 \%$ of pregnancy induced hypertension had been reported in a study of pregnant women attending antenatal clinics in a Teaching Hospital in South-South Ebeigbe, et al. [23]. Similarly, prevalence rates of hypertensive conditions of pregnancy range from $17 \%$ to $34.1 \%$ Singh, et al. [24]. In 2009, the occurrence of PIH ranges between $2 \%$ to $16.7 \%$ Abubakar, et al. [25]. In 2011, Enugu town had 3.3\% per 77 cases of
PIH out of 2337 cases Ugwu, et al. [26]. In 2014, according to Singh, et al. [27], the prevalence of hypertensive disorders was estimated to be higher than $17 \%$ in Nigeria. Akeju, et al. [28] suggested that women have health seeking behaviors, which range from buying over the counter drugs to relieve headache, consulting families on what to do with odema, epigastric pain and blurred vision, consulting a spiritual or traditional healer on convulsing and coming to hospital. All these health-seeking behaviors may delay coming to hospital, worsening the PIH complications. Between the periods of 1990 and 2015, 10.7 million maternal deaths were stated globally, in spite of the fact that maternal mortality ratio had fallen by $44 \%$ over these periods. WHO [29]. Out of this total number, developing countries accounts for about $99 \%$ of the global deaths in 2015, with Sub-Saharan Africa accounting for bumpily $66 \%$.

Study by WHO [29] showed that Nigeria and India are estimated to account for over one third of all maternal deaths globally in 2015, contributing $19 \%$ and $15 \%$ respectively. Furthermore, the study also revealed that in the West African sub-region, Nigeria with a maternal mortality ratio (MMR) of 814 ranks second, after Sierra Leone 1360 MMR. With this MMR, Nigeria could not meet the MDG5A target in 2015, which aims to reduce maternal mortality ratio by $75 \%$ of its 1990 level by 2015.Among the causes of maternal mortality, hypertension ranks second (14\%) after hemorrhage Say, et al. [30]. In Nigeria, hypertensive disorders of pregnancy could be a contributory factor to the rising prevalence of hypertension, which has been predicted to escalate up to 39.1 million by 2030, if the current inclination in figures continues Adeloye, et al. [31].

\section{Empirical Review}

Studies conducted by Butalia, et al. [32] and Regitz Zagrosek, et al. [33] revealed that there remain terminology and definition disagreements across international guidelines for hypertension. Hypertension itself has been defined over the years by diastolic or systolic readings alone, as well as by changes in pressures throughout pregnancy Chappell, et al. [34]. Similarly, limits for what is considered severe hypertension have been different. Semantics have clinical implications, and systematic reviews often have to compare studies or populations, which are assumed to be the same, rather than standardized Abalos, et al. [35]. Therefore, the International Society of the Study of Hypertension in Pregnancy (ISSHP) identified this as one of the factors for the range of controversies surrounding the treatment of hypertension during pregnancy and appointed a committee to address them beginning in 1998 Brown, et al. [36]. Moreover, studying several international guidelines, definitions are more standardized; however, there are still disagreements in sphygmomanometer intervals that define hypertension, precise definitions of proteinuria, the terms used to characterize blood pressure in the non-severe range, and even terminology used to classify the hypertensive disorders themselves 
Redman $[37,32,33]$. All of these reflect that the understanding of hypertensive disorders of pregnancy remains unsolidified and further research is necessary before a universal unanimity is reached on how to treat these disorders.

Hypertensive Disorder of Pregnancy (HDP) is defined as high blood pressure during pregnancy, is one of the direct causes of maternal and child mortality AOM [38]. It is measured by blood pressure level greater than $140 / 90 \mathrm{~mm} \mathrm{Hg}$ after 20 weeks of gestation. Austere forms of HDP are reflected through blood pressure intensities of $160 / 100 \mathrm{~mm} \mathrm{Hg}$ and more NHLBI [39]. Furthermore, studies by Magee, et al. [40] revealed that HDP are responsible for 70,000 maternal deaths globally, killing one woman every 11 minutes. HDP is the second leading cause of maternal mortality in Bangladesh, according to the Bangladesh Maternal Mortality Survey 2017, with approximately 24 percent of the country's maternal deaths caused by pre-eclampsia/eclampsia (PE/E) NIPORT [5], which affects women during pregnancy, childbirth, as well as postpartum. Factors, such as lack of health care provider capacities to detect, prevent, and manage PE/E, late referrals of HDP clients, late attendance and lack of antenatal care (ANC) and awareness about preeclampsia or eclampsia among communities have been associated as reasons for most of these preventable deaths Warren et al. [6].

\section{Theoretical Framework}

This study is anchored on two theories, which include: the Theory of Reasoned Action (TRA) and the Theory of Planned Behavior (TBP). Theory of Reasoned Action was formulated by Martin Fishbein and IcekAjzen towards the end of the 1960s. On the other hand, IcerkAjzen proposed the Theory of Planned Behaviour in 1985; which was an extension from the TRA. The Theory of Reasoned Action and Theory of Behaviour Planned combine two sets of belief variables, which are 'behavioural attitudes' and 'the subjective norms'. The behavioural attitudes are defined as the multiplicative sum of the individual's relevant likelihood and evaluation related to behavioural beliefs. On the other hand, subjective norms are referent beliefs about what behaviors others expect and the degree to which the individual wants to comply with others' expectations. The summary of the two theories suggest that a person's health behavior is determined by their intention to perform a behavior (behavioural intention) is predicated by a person's attitude toward the behavior, and the subjective norms regarding the behavior. The Theory of Reasoned Action has been criticized because it is said to ignore the social nature of human action Kippax [41]. These behavioural and normative beliefs are derived from individuals' perceptions of the social world they inhabit, and are hence likely to reflect the ways in which economic or other external factors shape behavioural choices or decisions.

In addition, there is a compelling logical case to the effect that the model is inherently biased towards individualistic, rationalistic, interpretations of human behavior. Its focus on subjective perception does not essentially permit it to take meaningful account of social realities. Individuals' beliefs about such issues are unlikely going to reflect the accurate potential and observable social facts. As such, the Theory of Planned Behaviour updated the Theory of Reasoned Action to include a component of perceived behavioural control, which brings about one's perceived ability to enact the target behavior. Actually, perceived behavioural control was added to the model to extend its applicability beyond purely volitional behaviours. Previous to this addition, the model was relatively unsuccessful at predicting behaviours that were not mainly under volitional control. Therefore, the Theory of Planned Behaviour proposed that the primary determinants of behaviour are an individual's Behavioural intention and perceived behavioural control. A constructive use of the TRA and TBP in research and public health intervention programmers might well contribute valuably to understanding issues related to health inequalities and the roles that other environmental factors have in determining health behaviours and outcomes. In spite of the criticism, the general theoretical framework of the TRA and TPB have been widely used in the retrospective analysis of health behaviours and to a lesser extent in predictive investigations and the design of health interventions Hardema, et al. [42]. This is why there is a connection between the study and the theory, since the tenets of the theories are located within the pore of the study.

\section{Methodology}

The study was conducted in Kabo Local Government Area of Kano State, Nigeria. It has an area of $341 \mathrm{~km}^{2}$ and a population of 153,828 NPC [43]. The study comprises of women within the reproductive ages of 14-45, pregnant and married in Kabo Local Government Area of Kano State. Women were purposively selected for the study not just because of their ability to conceive but they are the ones that do encounter pregnancy induce hypertension. Two nurses were selected from the Cottage Hospital in the local government based on their long working experiences and competencies in the facility. This makes a total sample of twenty one (22) respondents. The study used Interpretative Phenomenological Analysis (IPA). Purposive sampling method was used in selecting the respondents for in-depth interview. Kabo Cottage Hospital was purposively selected, which is bigger compare to other two in the local government with an average of 52Anti-natal Care Attendance (ANC) and 36 live births in the facility monthly. The 22 respondents were interviewed by structural interview method, using tape recorder, note book and biro as data gathering instruments. The respondents were tag with codes like respondent 1, 2, 3, 4 and 5, etc. Based on the in-depth interview method, the data was presented using interpretative analysis. 


\section{Findings and Discussion}

In attempt to mention the signs of pregnancy induced hypertension, respondent 1 states that: "signs of pregnancy induced hypertension are many, however, she stated the following as part of the signs as follows: chest pain and headache". Corroborating, respondent 2 put forward the followings as some of the signs: "blurred vision and dizziness," while respondents 3, 4, 5 and 6 agreed that pedal oedema and epitaxies are also among the signs. Similarly, a study by Haque [44] stated that high blood pressure, headache, blurred vision, swelling in extremities, nausea or vomiting, fatigue and sudden weight gain are among the signs of pregnancy induced hypertension. Furthermore, Magee, et al. [45] noted that the patient with severe PIH should be evaluated for signs of preeclampsia, as generalized edema, including that of the face and hands, rapid weight gain, blurred vision or scotomata (ie, areas of diminished vision in the visual field), throbbing or pounding headaches, epigastric or pain associated with upper quadrant, oliguria (urinary output $<500 \mathrm{~mL} / \mathrm{d}$ ), nausea with or without vomiting, hyperactive reflexes, chest pain, tightness and shortness of breath. Blood pressure should be measured and recorded at every prenatal visit, using the correct-sized cuff, with the patient in a seated position. Leeman [46] said gestational hypertension is a clinical diagnosis confirmed and established by at least two accurate blood pressure tests in the same arm in women without proteinuria, with readings of $\geq 140 \mathrm{~mm} \mathrm{Hg}$ systolic and $\geq 90 \mathrm{~mm}$ Hg diastolic.

It should then be determined whether the patient's hypertension is mild or severe (i.e. blood pressure $>160 / 110 \mathrm{~mm}$ $\mathrm{Hg}$ ). When asked about the risk factors associated with pregnancy induced hypertension, respondent 1 states that: "parts of the risk factors associated with pregnancy induced hypertension are indefinitely large numerically, nonetheless, she listed the followings as part of the risk factors: "multiple gestations, elderly prim gravida and high parity." Moreover, respondent 2 stated "polyhydramnios and essential hypertension," while respondent 3 stated "kidney disease." All the respondents agreed that high salt intake (in diet), obesity and stress also contribute to the risk factors associated with pregnancy induced hypertension. Bansode [47] also found that some of the factors associated with pregnancy induced hypertension include first pregnancy, new partner/paternity, age $<18$ years or $>35$ years, black race, obesity (Body Mass Index, BMI $\geq 30$ ), inter-pregnancy interval $<2$ years or $>10$ years and use of selective serotonin reuptake inhibitors (SSRIs) beyond the first trimester; while placental or fetal risk factors include multiple gestation, hydropsfetalis, gestational trophoblastic disease and triploidy. Similarly, Umegbolu [48] reported that the overall incidence of PIH among pregnant women in Enugu State, Southeast Nigeria (2006-2015) was found to be 5.9\%.
The study identified annual variations in the incidence of PIH (rising and falling trends between 2006 and 2015) among the pregnant women. The incidence of PIH was highest among those women above 35 years (13.5\%), compared to those whose age is less than 20 years (9.1\%) and those between 20-35 years (5.1\%). The occurrence was also higher in the nulliparous (prim gravidae) (7.7\%) compared to the multiparous ones (5.5\%). Furthermore, Anujeet, et al. [49] stated that hypertension, collagen vascular disease, obesity, black race, insulin resistance, diabetes mellitus, gestational diabetes, increased serum testosterone concentrations and thrombophilia, clotting disorders, and hemolysis, elevated liver enzymes, low platelet count (HELLP) syndrome are also responsible risk factors for PIH. Similarly, age and parity are two of the identified maternal risk factors for the development of pregnancy induced hypertension. Extreme ages (age below 20 years and above 35 years) are known to be associated with higher incidence of pregnancy induced hypertension. Like the overall incidence of pregnancy induced hypertension, incidence among various age groups and parity varies from place to place. In Karachi, Rehman, et al. [50] found an incidence of $9 \%$ among older women and $27 \%$ among prim gravidae. However, Sajith, et al. [51] reported an incidence of pregnancy induced hypertension of $41.3 \%$ among 18-22 years old patients in their study.

Furthermore, Ahmed, et al. [52] states that educational attainment of women is also a factor that contributes to developing pregnancy induced hypertension. This is because illiterate mothers are more likely to suffer from hypertension during pregnancy than their counter parts. There is every tendency that educated mothers are likely to be aware of pregnancy related complications and its consequences, marry educated husband that facilitate couples discussion on maternal health care utilization, likely to be autonomous in decision making and hence meeting her reproductive needs. Generally, education increases health seeking behaviours of women. The study of Swati, et al. (2014) stated being unmarried as a risk factor and prognosticator of $\mathrm{PIH}$, which is an exceptional result from this study. The study further explains that although marital status is hardly reported as a risk factor in the literature, a possible explanation in a resource poor country like Nigeria could be due to worry about the financial burden of single parenting in environment, which lacks any form of child welfare support. Moreover the stigma of having a child outside marriage is a potential source of concern and anxiety. In addition, Zusterzeel, et al. [53] had emphasized immunological intercourse as the prevention of this maternal-fetal conflict called pregnancy induced hypertension. There is an association of pregnancy-induced hypertension with duration of sexual co-habitation before the first conception. Male ejaculation is said to protect a woman if she has been repeatedly been exposed to it. 
Regarding the prevention and management of pregnancy induced hypertension, respondent 10 states that "regular antenatal care and regular check-up/ BP checking are sine qua non." Corroborating, all the respondents agreed that low salt intake, avoiding alcohol, regular intake of water drug therapy for severe hypertension, treatment of underlying medical conditions like kidney problem and avoidance of strenuous exercises or stress are parts of the prevention and management. The findings of the studies are similar with Singh [54] that PIH can be prevented and managed by low salt intake, drinking at least eight glasses of water a day, regular BP check-up, increase the amount of protein-rich foods and decrease the amount of fried and junk foods, regular exercise and enough rest, elevate your feet several times during the day, avoid drinking alcohol and beverages containing caffeine, prescription of drug therapy and additional supplements by a medical doctor. In drug management of pregnancy induced hypertension, ACOG [55] states that labetalol and extended-release nifedipine are first line drugs as they are safe and effective. Similarly, Morgan, et al. [56] emphasized, although beta-blockers other than labetalol are less well investigated, if labetalol cannot be used metoprolol, propranolol, pindolol and acebutolol may be considered. Extendedrelease nifedipine is the most widely used calcium channel blocker.

Table 1: Relatively Safe Antihypertensive Drugs in Pregnancy.

\begin{tabular}{|c|c|c|}
\hline Antihypertensive & Advice & Potential Adverse Effects \\
\hline ACE inhibitors & Contraindicated & $\begin{array}{c}\text { Teratogenic in first trimester, fetal renal dysfunction, } \\
\text { oligohydramnios and skull hypoplasia in second and third } \\
\text { trimesters }\end{array}$ \\
\hline Angiotensin receptor blockers & Contraindicated & $\begin{array}{c}\text { Teratogenic in first trimester, fetal renal dysfunction and } \\
\text { oligohydramnios in second and third trimester }\end{array}$ \\
\hline Diuretics & Avoid & Fetal electrolyte disturbances, reduction in maternal blood volume \\
\hline Beta blockers (except labetalol and oxprenolol) & Avoid & $\begin{array}{c}\text { Fetalbradycardia, long-term use of atenolol associated with fetal } \\
\text { growth restriction }\end{array}$ \\
\hline Calcium channel antagonist (except nifedipine) & Avoid & Maternal hypotension and fetal hypoxia \\
\hline
\end{tabular}

In an instance when there is no desire to breastfeed and adequate contraception is used, the choice of antihypertensive drug is the same as for any other non-pregnant woman or patient. While

(Table 2) shows the antihypertensive drugs used in pre-eclampsia, which are the same as those used to treat chronic and PIH Lowe et al. [59-61].

Table 2: Antihypertensive Drugs during Breastfeeding.

\begin{tabular}{|c|c|c|c|c|}
\hline Antihypertensive & Class & Starting Dose & Maximum Dose & Important Adverse Effects \\
\hline Labetalol & Beta blocker & 100-200mg twice a day & $400 \mathrm{mg}$ three times a day & $\begin{array}{l}\text { Bradycardia, bronchospasm, } \\
\text { transcient scalp tingling }\end{array}$ \\
\hline Oxprenolol & Beta blocker & 40-80mg twice daily & 80-160mg twice daily & Bradycardia, bronchospasm \\
\hline Nifedipine & Calcium channel antagonist & $\begin{array}{l}\text { 10mg twice a day, } 30 \mathrm{mg} \\
\text { daily controlled release }\end{array}$ & $\begin{array}{c}20-40 \text { mg twice a day, } \\
\text { 120mgdaily controlled } \\
\text { release }\end{array}$ & $\begin{array}{c}\text { Severe headache, peripheral } \\
\text { oedema }\end{array}$ \\
\hline Methyldopa & Centrally-acting & 20mg twice a day & $50 \mathrm{mmg}$ four times a day & $\begin{array}{l}\text { Sedation, light-headedness, } \\
\text { dry mouth, nasal } \\
\text { congestion, haemolytic } \\
\text { anaemia, depression }\end{array}$ \\
\hline
\end{tabular}




\begin{tabular}{|c|c|c|c|c|}
\hline Hydralazine & vasodilator & $25 \mathrm{mg}$ twice a day & $50-200 \mathrm{mg}$ total daily dose & $\begin{array}{l}\text { Flushing, headache, lupus- } \\
\text { like syndrome }\end{array}$ \\
\hline Prazosin & Alpha blocker & $0.5 \mathrm{mg}$ twice a day & 3mg total daily dose & Postural hypotension \\
\hline
\end{tabular}

Source: Donovan [58]

\section{Conclusion}

The strains of maternal mortality remain unduly borne by women in less-developed countries, particularly in sub-Saharan Africa. Between the periods of 1990 and 2015, 10.7 million maternal deaths were stated globally, in spite of the fact that maternal mortality ratio had fallen by $44 \%$ over these periods. Out of these total numbers, developing countries account for about $99 \%$ of the global deaths in 2015, with Sub-Saharan Africa accounting for bumpily $66 \%$ with 201,000 deaths. PIHs are responsible for 70,000 maternal deaths universally, killing one woman every 11 minutes. Nigeria, in 2014, recorded the prevalence of pregnancy induced hypertension and was estimated to be about $20.8 \%$ among pregnant women attending antenatal clinics in Teaching Hospitals in South-South. Based on these problems, the findings of this study attest that the signs of pregnancy induced hypertension in Kabo Local Government include chest pain, headache, blurred vision, dizziness, pedal oedema and epitaxies. Finally, the risk factors are multiple gestations, elderly prim gravida, high parity, polyhydramnios, essential hypertension, kidney disease, high salt intake (in diet), obesity and stress.

\section{Recommendations}

The study recommends the following, based on the finding of the study:

1. The study recommends that pregnant women in Kabo Local Government should visit the hospital regularly; especially to check their blood pressure.

2. The women in Kabo Local Government should be educated about the signs of pregnancy induced hypertension. This will help them to know how to seek for medical services early.

3. Finally, women in Kabo Local Government should be educated on factors that will assist them to stay healthy and avoid pregnancy induced hypertension.

\section{References}

1. Sharma S, Sidhu H, Kaur S (2016) Analytical study of intrauterine fetal death cases and associated maternal comditions. Int J Appl Basic Med Res 6(1): 11-13.

2. Mohan K, Mishra PC, Singh DK (2013) Clinical profile of birth asphyxia in newborn. Int J Sci Tech 3(1): 10-19.

3. Xiong T, Mu Y, Liang J, Zhu J, Li X, et al. (2018) Hypertensive disorders in pregnancy and stillbirth rates: A facility-based study in China. Bulletin of the World Health Organization 96(8): 531-539.
4. Magee LA, Von Dadelszen P, Stones W, Mathai M (2016) The FIGO textbook of pregnancy hypertension: An evidence-based guide to monitoring, prevention and management.

5. (2018) National Institute of Population Research and Training (NIPORT), Mitra and Associates and ICF. Bangladesh Demographic and Health Survey 2017-18: key indicators. Dhaka and Rockville, MD, USA: NIPORT, Mitra and Associates, ICF.

6. Warren C, Hossain SMI, Nur RA, Sultana K, Kirk K, et al. (2015) Landscaping report on preeclampsia and eclampsia in Bangladesh. Washington, DC: Population Council.

7. Deruelle P, Coudoux E, Ego A, Houfflin Debarge V, Codaccioni X, et al. (2006) Risk factors for postpartum complications occurring after preeclampsia and HELLP syndrome. A study in 453 consecutive pregnancies. Eur J Obstet Gynecol Reprod Biol 125(1): 59-65.

8. (2015) Royal College of Obstetricians and Gynecologists. Green-top guideline: Reducing the risk of thrombosis and embolism during pregnancy and the puerperium.

9. Melchiorre K, Sutherland GR, Liberati, M, Thilaganathan B (2011) Preeclampsia is associated with persistent postpartum cardiovascular impairment. Hypertension 58(4): 709-715.

10. (2011) National Clinical Guideline Centre 7 diagnosis of hypertension, 7.5 link from evidence to recommendations. Hypertension (NICE CG 127). National Institute for Health and Clinical Experience, pp. 102- 122.

11. (2018) United Nations. About the Sustainable Development GoalsNew York: United Nations.

12. Graham W, Woodd S, Byass P, Filippi V, Gon G, et al. (2016) Diversity and divergence: The dynamic burden of poor maternal health. Lancet 388(10056): 2164-275.

13. Payne BA, Hanson C, Sharma S, Magee LA, Von Dadelszen P (2017) Epidemiology of the hypertensive disorders of pregnancy. In: Magee LA, von Dadelszen P, Stones W, Mathai M (Eds.)., The FIGO textbook of pregnancy hypertension. London: Global Library of Women's Medicine, 201.

14. (2014) Ethiop J Health Sci. Suppl, pp. 15-18.

15. Srinivas SK, Stamilio DM, Stevens EJ, Odibo AO, Peipert JF, et al. (2007) Predicting failure of a virginal birth attempt after caesarean delivery. Obstetrics and Gynaecology 109(4): 800-805.

16. Palacios C, Pena Rosas JP (2011) Calcium supplementation during pregnancy for preventing hypertensive disorders and related problems.

17. Livingston JC, Livingston LW, Ramsey RB, Mabie C, Sibai BM (2003) Magnesium sulfate in women with mild preeclampsia: A randomized controlled trial. Obstetrics and Gynecology 101(2): 217-220.

18. Heard AR, Dekker GA, Chan A, Jacobs DJ, Vreeburg SA, et al. (2004) Hypertension during pregnancy in South Australia, part 1: Pregnancy outcomes. Australian and New Zealand Journal of Obstetrics and Gynaecology 44(5): 404-409.

19. Dolea C, Abou ZC (2003) Global burden of hypertensive disorders of pregnancy in the year 2000, evidence and information for policy (EIP), World Health Organizaton. Geneva, Switzerland.

20. Abeysena C, Jayawardana P, Seneviratne RA (2010) Effect of psychosocial stress on maternal complications during pregnancy: A cohort study. Int $\mathrm{J}$ of Collaborative Research on International Medicine and Public Health 2(12): 436-448. 
21. Bateman BT, Bansil P, Hernandez Diaz S, Mhyre JM, Callaghan WM, et al. (2012) Prevalence, trends, and outcomes of chronic hypertension: A nationwide sample of delivery admissions. Am J Obstet Gynecol, 206(2): 134-138.

22. Malha L, August P (2015) Secondary hypertension in pregnancy. Curr Hypertens Rep 17(7): 53.

23. Ebeigbe PN, Igberase GO, Aziken ME (2007) Hypertensive disorders in pregnancy: Experience with 442 recent consecutive cases in Benin City, Nigeria. Nig Med J 48(4): 94-98.

24. Singh S, Ahmed EB, Egondu SC, Ikechukwu NE (2014) Hypertensive disorders in pregnancy among pregnant women in a Nigerian Teaching Hospital. Niger Med 55(5): 384-388.

25. Abubakar RA, Abdullahi HZ, Jibril MH, Dauda M, Poopola A (2009) Maternal ethnicity and severity of preeclampsia in Northern Nigeria. Asian Journal of Medical Sciences 1(3): 104-107.

26. Ugwu EO, Dim C, Okonkwo CD, Nwankwo T (2011) Maternal and perinatal outcome of severe preeclampsia in Enugu, Nigeria after introduction of magnesium sulphate. Nigerian Journal of Clinical Practice 14(4): 418-421.

27. Singh S, Ahmed EB, Egondu SC, Ikechukwu NE (2014) Hypertensive disorders in pregnancy among pregnant women in a Nigerian Teaching Hospital. Nigerian Medical Journal 55(5): 384-390.

28. Akeju DO, Oladapo OT, The CLIP Nigeria Feasibility Working Group (2016) Determinants of health care seeking behaviour during pregnancy in Ogun State, Nigeria. Reproductive Health 13(1): 68-79.

29. (2015) WHO, UNICEF, World Bank Group, UNPD. Trends in maternal mortality: 1990-2015.

30. Say L, Chon D, Gemmill A, Turicalp O, Moller AB, et al. (2014) Global causes of maternal death: A WHO systematic analysis. The Lancet G Health 2(6): e323-333

31. Adeloye D, Basquill C, Aderemi AV, Thompson JY, Obi FA (2015) An estimate of the prevalence of hypertension in Nigeria: A systematic review and meta-analysis. J Hyp 33(2): 230-242.

32. Butalia S, Audibert F, Cote AM, Firoz T, Logan AG, et al. (2018) Hypertension Canada's 2018 guidelines for the management of hypertension in pregnancy. Can J Cardiol 34(5): 526-531.

33. Regitz Zagrosek V, Roos Hesselink JW, Bauersachs J, Blomstrom Lundqviat C, Cifkova R, et al. (2018) ESC guidelines for the management of cardiovascular diseases during pregnancy. Eur Heart J 39: 3165-3241.

34. Chappell L, Poulton L, Halligan A, Shennan AH (2005) Lack of consistency in research papers over the definition of pre-eclampsia. Br J Obstet Gynaecol 106(9): 983-985.

35. Abalos E, Duley L, Steyn DW, Gialdini C (2018) Antihypertensive drug therapy for mild to moderate hypertension during pregnancy. Cochrane Database Syst Rev 10(10): CD002252.

36. Brown MA, Lindheimer MD, De Swiet M, Assche A, Moutquin JM (2001) The classification and diagnosis of the hypertensive disorders of pregnancy: statement from the International Society for the Study of Hypertension in Pregnancy (ISSHP). Hypertens Pregnancy 20(1): IX-XIV.

37. Redman CW (2011) Hypertension in pregnancy: The NICE guidelines. Heart 2011 97(23): 1967-1969.

38. (2012) Association of Ontario Midwives (AOM). Clinical practice guideline no. 15: Hypertensive disorder of pregnancy.

39. (2000) National Heart, Lung, and Blood Institute, (NHLBI). Report of the national high blood pressure education program working group on high blood pressure in pregnancy. Am J Obstet Gynecol 183: 1-22.
40. Magee LA, Von Dadelszen P, Stones W, Mathai M (2016) The FIGO textbook of pregnancy hypertension: an evidence based guide to monitoring, prevention and management.

41. Kippax S, Crawford J (1993) Flaws in the theory of reasoned action. In the theory of reasoned action: its application to AIDS preventive behaviour. In: Terry DJ, Gallois C, McCamish MM (Eds.)., Pergamon Press, pp. 253-269.

42. Hardema W, Johnston M, Johnston D, Bonetti D, Wareham N, et al. (2002) Application of the theory of planned behavior in behavior change interventions: A systematic review. Psychology and Health 17(2): 123158.

43. (2006) NPC. The report of the Nigeria's National Population Commission.

44. Haque MM, Sarkar NC (2020) Prevalence of pregnancy induced hypertension among the pregnant women: A study in Shaheed Ziaur Rahman Medical College Hospital, Bogura, Bangladesh. Saudi J Med Pharm Sci 6(1): 53-57.

45. Magee LA, Helewa M, Moutquin JM, Von Dadelszen P (2008) Hypertension guideline committee; strategic training initiative in research in the reproductive health sciences (STIRRHS) scholars. Diagnosis, evaluation, and management of the hypertensive disorders of pregnancy. J Obstet Gynaecol Can 30(3): S1-S48.

46. Leeman L, Fontaine P (2008) Hypertensive disorders of pregnancy. Am Fam Physician 78(1): 93-100.

47. Bansode BR (2012) Managing hypertension in pregnancy. Med Update 22: $150-156$.

48. Umegbolu EI, Ogamba JO (2017) Incidence of gestational hypertension among pregnant women (2006-2015) in Enugu State, Southeast Nigeria: A retrospective study. Int J Community Med Public Health 4(2): 357-362.

49. Anujeet R, Singh A, Kapoor S (2016) Pregnancy induced hypertension: A retrospective study of 200 cases of pregnant women. Journal of Dental and Medical Sciences (IOSR-JDMS) 15(6): 3643.

50. Rehman MO, Din SU, Siddiqui MA, Rehman S (2003) Incidence of women having pregnancy induced hypertension in Karachi. Pak J Pharmacology 20(1): 5-8.

51. Sajith M, Nimbargi V, Modi A, Sumariya R, Pawar A (2014) Incidence of pregnancy induced hypertension and prescription pattern of antihypertensive drugs in pregnancy. Int J Pharm S Res (IJPSR) 5(04): 163-170.

52. Ahmed SS, Sultana N, Begum ML, Sultana L, Abedin MF, et al. (2017) Pregnancy induced hypertension and associated factors among pregnant women. J Gynecol Women's Health 3: 1-6.

53. Zusterzeel PL, teMorsche R, Raijmakers MTM, Roes EM, Peters WH, et al. (2002) Paternal contribution to the risk for preeclampsia. J Med Genet 39: 44-45.

54.Singh V, Srivastava M (2015) Associated risk factors with pregnancy induced hypertension: A hospital based KAP study. Int J Med Public Health 5(1): 59-62.

55. (2019) ACOG Practice bulletin no. 202: Gestational hypertension and preeclampsia. Obstet Gynecol 133: 1-25.

56. Morgan J, Kogutt B, Meek C, Stehel E, McIntire DD, et al. (2018) Pharmacokinetics of amlodipine besylate at delivery and during lactation. Pregnancy Hypertens 11: 77-80.

57. Colaceci S, Giusti A, Chapin EM, Nortarangelo M, Angelis AD, et al. (2015) The difficulties in antihypertensive drug prescription during lactation: Is the information consistent? Breastfeed Med 10(2015): 468-473.

58. Donovan P (2012) Hypertensive disorders of pregnancy. Aust Prescr 35: 47-50. 
59. Lowe SA, Brown MA, Dekker GA, Gatt S, McLintock CK, et al. (2009) Guidelines for the management of hypertensive disorders of pregnancy 2008. Aust N Z J Obstet Gynaecol 49(3): 242-246.

60. Umegbolu EI, Ogamba JO (2017) Incidence of gestational hypertension among pregnant women (2006-2015) in Enugu State, Southeast Nigeria: A retrospective study. Int J Community Med Public Health 4(2): 357-362.

ISSN: 2574-1241

DOI: $10.26717 /$ BJSTR.2021.39.006321

Aondover Eric Msughter. Biomed J Sci \& Tech Res

(C) (P) This work is licensed under Creative

Submission Link: https://biomedres.us/submit-manuscript.php
61. Notion G, Emmanuel T, Gerald S, Addmore C, Mufuta T, et al. (2009) Determinants of perinatal mortality.

$\begin{array}{ll}\text { BIOMEDICAL } & \text { Assets of Publishing with us } \\ \text { RESEARCHES } & \text { - Global archiving of articles } \\ \text { - Immediate, unrestricted online access }\end{array}$

